\title{
Genetic variation and diversity of pearl millet [Pennisetum glaucum (L.)] genotypes assessed for millet head miner, Heliocheilus albipunctella resistance, in West Africa
}

\author{
Riyazaddin Mohammed (D) - Prakash I. Gangashetty (D) Laouali Karimoune • \\ Niango Malick Ba (1)
}

Received: 31 July 2019/Accepted: 31 August 2020

(C) Springer Nature B.V. 2020

\begin{abstract}
Pearl millet (Pennisetum glaucum L.), the major source of minerals and dietary energy for people living in the semi-arid regions of Sahel, is regularly damaged by millet head miner, Heliocheilus albipunctella. In order to identify the plant-based resistance sources for millet head miner along with high grain $\mathrm{Fe}$ and $\mathrm{Zn}$, we have screened forty pearl millet genotypes, using an artificial infestation method. Analysis of variance revealed significant differences in the genotypes tested for head miner resistance. The genotypes Gamoji, ICMP 177001, ICMP 177002, ICMV 177003, ICMV IS 90311, LCIC9702, Souna 3, ICMV IS 94206 and PE08043 exhibited antibiosis resistance mechanism to Heliocheilus albipunctella with appreciable agronomy and grain yield when compared with the susceptible check ICMV IS 92222. The genotypes Faringuero, ICMV 167005, ICMV IS 99001, Sadore local, SOSAT-C88, and ICMP 177004 exhibited tolerance to head miner damage with good per se performance. The genotypes ICMP 177001, ICMP 177002, ICMV 177003, and Moro exhibited resistance to millet head miner and had consistent grain $\mathrm{Fe}$ content across seasons (ranging from 44 to $70 \mathrm{ppm}$ ). Association between the head miner resistance and morphological traits showed a positive and
\end{abstract}

R. Mohammed $(\bowtie) \cdot$ P. I. Gangashetty

L. Karimoune · N. M. Ba

International Crops Research Institute for the Semi-Arid

Tropics, BP 12404, Niamey, Niger

e-mail: M.Riyazaddin@cgiar.org significant correlation of larval production index (\%) with head miner damage $\left(\mathrm{r}=0.59^{* *}\right)$. Grain $\mathrm{Fe}$ and Zn contents exhibited negative association with panicle length and grain yield indicating proper care should be taken in breeding for these traits. Hence, the identified resistance sources can be effectively utilized in breeding head miner resistant pearl millet OPV's/ hybrids, with high grain yield including $\mathrm{Fe}$ and $\mathrm{Zn}$ concentrations, to overcome the hunger and malnutrition seen in populations living in the semi-arid tropics.

Keywords Pearl millet - Millet head miner . Heliocheilus albipunctella $\cdot$ Host plant resistance . Antibiosis · Tolerance

\section{Introduction}

Pearl millet [Pennisetum glaucum (L.) R. Br.], is a highly cross-pollinated cereal, and is the sixth most important crop globally (Yadav and Rai 2013). It is diploid $(2 \mathrm{n}=14)$ with high photosynthetic efficiency and biomass production potential. It is grown in over 40 countries in 31.2 million hectares of land with a productivity of $910.9 \mathrm{~kg} / \mathrm{ha}$ (FAOSTAT 2017). It is the staple food grain for people living in semi-arid and arid regions, including some of the world's poorest smallholder farm families and those most threatened by climate change (Schlenker and Lobell 2010). It 
provides a reliable source of feed, fodder, fuel, and construction material in the Sahel, where rain-fed agriculture is practiced (Hash 1999). The main pearl millet cultivation areas of semi-arid regions have lowfertility, light-textured soils, and receive $<500-600 \mathrm{~mm}$ of rainfall annually, where sorghum and maize are subject to frequent crop failures (Harinarayana et al. 1999). Pearl millet can withstand periods of water-limited conditions and still produce biomass and grain, feeding the poor people and the cattle of West and Central Africa (WCA) (Poncet et al. 1998; Bidinger and Hash 2004; Stich et al. 2010).

Niger is the second-largest pearl millet growing country in the world after India, with an annual area of $7.2 \mathrm{~m}$ ha and grain production of $3.88 \mathrm{~m} \mathrm{t}$ (FAOSTAT 2016). Grain yield is very low $(537.5 \mathrm{~kg} / \mathrm{ha})$ in Niger and other Sahelian countries compared to the potential of the crop (3.0 t/ha) and the average $1.27 \mathrm{t} \mathrm{ha}^{-1}$ in India (FAOSTAT 2016). The low grain yields in the Sahelian countries are due to many constraints, including low soil fertility, drought, use of local cultivars with low yield potential, diseases, parasitic weeds, and insect pests (Bidinger and Hash 2004; Gahukar and $\mathrm{Ba}$ 2019). Even though local varieties have low yield and quality potential, they can still be utilized in breeding due to high adaptability.

Globally, some 300 insect pests have been reported to feed on pearl millet (Nwanze and Harris 1992). Among these insect pests, millet head miner (MHM), Heliocheilus albipunctella, (de Joannis) (Lepidoptera: Noctuidae) is one of the most devastating species encountered in the Sahel (Gahukar and Ba 2019). Damage by MHM is due to larvae feeding on the panicle and preventing grain formation. As the MHM larvae feed between the rachis and flowers, they form a characteristic spiral pattern on the millet panicle, and yield losses range from 16 to $85 \%$ (Krall et al. 1995; Youm and Owusu 1998; Gahukar and Ba 2019). Infestations of MHM are most severe in the drier zones of the Sahel (Nwanze and Harris 1992; Gahukar and Ba 2019), where short-duration cultivars of this crop offer opportunities to escape the threat of terminal drought stress.

Several measures were undertaken to control MHM, including the planting of pest tolerant/resistant cultivars, the application of chemical pesticides, and the abundance of natural enemies that have had significant impacts on larval mortality but have limited application (Gahukar and Ba 2019). Control with pesticides is not realistic for subsistence farmers because of their prohibitive cost, their limited availability, lack of trained manpower, and risks to health and the environment. Biological control with release of the parasitoid wasp Habrobracon (= Bracon) hebetor Say (Hymenoptera: Braconidae) resulted in parasitism of $80 \%$ of the MHM larvae and resulted in an increase of $30 \%$ grain yield (Payne et al. 2011; Ba et al. 2013; Baoua et al. 2014). Even though proven effective, means for making biocontrol agents available at large scale is still under development (Guerci et al. 2018; Kabore et al. 2019). Therefore, host plant resistance (HPR) can be exploited to complement the ongoing biological control efforts as an integrated pest management strategy for MHM.

Apart from MHM, micronutrient malnutrition is one of the alarming factors globally. Of several micronutrients, deficiencies in iron $(\mathrm{Fe})$ and zinc (Zn) have been reported to be the most important public health problems, leading to anemia and stunted growth, affecting more than two billion people worldwide. Iron and Zinc deficiency can also impair the immune system. Biofortification of the staple crops has the potential to be a more sustainable and costeffective approach to address micronutrient malnutrition among vulnerable populations and has the advantage of unhindered and ready consumer acceptance (Dwivedi et al. 2012). Pearl millet grain serves as a significant source of iron and zinc contents for the people living in WCA, where it is grown widely across the region. International Crops Research Institute for the Semi-Arid Tropics (ICRISAT), released the first biofortified variety, Chakti, to combat micronutrient malnutrition in WCA in 2017. In the past, host plant resistance for MHM has been explored but has never been fully investigated (Gahukar and $\mathrm{Ba}$ 2019). The importance of grain $\mathrm{Fe}$ and $\mathrm{Zn}$ concentration of pearl millet triggers breeding for these traits along with MHM resistance.

Hence, these findings have served the basis for the current study, which aimed to identify the resistance sources for MHM with high grain Fe and $\mathrm{Zn}$ contents and the major morphological and agronomic traits associated with MHM resistance. 


\section{Materials and methods}

Test material

The experiments were conducted at ICRISAT-Sahelian center, Sadore located at $13^{\circ} 15^{\prime} \mathrm{N}$ latitude and longitude $2^{\circ} 18^{\prime} \mathrm{E}$, and is $240 \mathrm{~m}$ above sea level. Forty diverse pearl millet genotypes [open pollinated varieties (OPV's), germplasm/populations, improved varieties specific to West and Central Africa] were evaluated for MHM resistance and grain $\mathrm{Fe}$ and $\mathrm{Zn}$ contents (Table 1).

\section{Experimental design}

The test genotypes including the susceptible check were sown in a randomized complete block design with three replications, during the rainy seasons in 2017 and 2018. A basal dose of fertilizer (NPK 15:15:15@100 kg/ha) was applied for raising the crop. Each of the test genotypes was sown in two rows with a row length of $4.8 \mathrm{~m}$, row to row spacing of $0.75 \mathrm{~m}$ and with a spacing of $0.80 \mathrm{~m}$ between the plants, a usual farmer practice in Niger. The seeds were sown manually at a depth of $5 \mathrm{~cm}$ using the field attendants. The test genotypes were thinned to two plants per hill at 14 days after emergence (DAE) and supplied with urea $(46 \% \mathrm{~N})$ at the dose of $2 \mathrm{~g} /$ hill. Manual weeding was carried out whenever necessary. No irrigation or pesticides were applied to the crop.

\section{Artificial infestation}

Three panicles per genotype, per replication, were used for artificial infestation with MHM using the technique developed by Youm et al. (2001). The panicles were randomly selected at panicle boot stage and individually covered screen head-cage (thin cotton cloth of dimensions $45 \mathrm{~cm} \times 100 \mathrm{~cm}$, supported with a cylindrical wire mesh of $20 \mathrm{~cm} \times 90$ $\mathrm{cm}$ as a skeleton), to avoid the predators and allow the panicle to flourish naturally (Fig. 1). At one-third panicles heading stage, each selected panicle was infested with 40 eggs of the MHM. To obtain eggs, MHM adult females were caught daily from light traps that were set up on the ICRISAT Sadore campus and allowed to lay eggs overnight on sections of earlyplanted pearl millet panicle in oviposition cages in the laboratory. Twenty MHM eggs were grouped on a sticky white rectangular piece of paper $(0.5 \mathrm{~cm} \times 0.5$ $\mathrm{cm}$ ) and pinned to the millet panicle. Each panicle was pinned with 2 pieces of paper bearing 40 eggs in total. After infestation, the panicles were kept covered with the screen cloth-cages and monitored daily to keep off insects and ants as well as to maintain the cage structure. Another set of three panicles/genotype/ replication was randomly selected as controls and covered with the same head cages to record the grain yield.

\section{Observations}

Data on head miner damage, agronomic, and morphological parameters were recorded. At harvest, the screen cages were carefully removed and the panicles were cut and visually assessed to score the damage and also count the larvae and pupae present in the cage. The head miner damage is scored at 1-9 scale (where $1=$ Panicle with no damage or with single mine or 0 $10 \%$ damage and $9=$ Panicle with $>80 \%$ damage) (Youm and Kumar 1995). The genotypes with damage score of 1-5 are considered as resistant and the genotypes with damage rating $>5$ are considered as susceptible (Youm et al. 2001). While removing the cage, the number of larvae and pupae (dead or alive) of MHM was recorded. The larvae and the pupal count was used to calculate the larval production index (LPI). The larval production index (LPI), which represent the percentage of eggs that developed to larvae and pupae stage was calculated for each genotype using the following formula:

$\mathrm{LPI}(\%)=\frac{\text { Number of larvae }(\text { dead or alive })+\text { Number of pupae }}{\text { Total number of eggs used for infestation }} \times 100$

Based on the mean performance of the genotypes the damage score of $<5$ and LPI lower than the total mean were considered as resistant with antibiosis mechanism and the genotypes with damage score of $<5$ and with LPI higher than the total mean as tolerant (recovery resistance) to MHM.

The agronomic desirability of the test genotypes was scored from 1 to 9 ( $1=$ good with productive potential and lower/no insect damage and $9=$ poor productive potential with susceptibility to insect pests). Days to $50 \%$ flowering was recorded when $50 \%$ of the plants in the test plot had attained the anthesis. The plant height of three randomly selected plants per replication was recorded at maturity. 
Table 1 Expression of resistance to millet head miner, Heliocheilus albipunctella in pearl millet, Pennisetum glaucum L., ICRISAT, Niamey, Niger

\begin{tabular}{|c|c|c|c|c|c|}
\hline Genotype & $\begin{array}{l}\text { Head miner } \\
\text { damage score }^{\mathrm{a}}\end{array}$ & $\begin{array}{l}\text { Number of } \\
\text { larvae/panicle }\end{array}$ & $\begin{array}{l}\text { Number of } \\
\text { pupae/panicle }\end{array}$ & $\begin{array}{l}\text { Larval production } \\
\text { index (LPI) }(\%)\end{array}$ & $\begin{array}{l}\text { Agronomic } \\
\text { appreciation score }^{\mathrm{b}}\end{array}$ \\
\hline ICMV IS 89305 & 3.56 & 3.00 & 1.22 & 10.56 & 7.00 \\
\hline ICMV IS 90309 & 6.11 & 8.78 & 0.67 & 23.61 & 7.33 \\
\hline Chakti & 5.11 & 10.33 & 1.56 & 29.72 & 3.00 \\
\hline Faringuero & 4.00 & 10.22 & 1.11 & 28.33 & 5.67 \\
\hline Gamoji & 2.17 & 4.83 & 0.39 & 13.06 & 5.33 \\
\hline GB 8735 & 4.89 & 10.67 & 1.33 & 30.00 & 3.00 \\
\hline IBMV 8402 & 4.33 & 11.00 & 1.56 & 31.39 & 5.33 \\
\hline ICMV 177001 & 5.22 & 13.33 & 1.56 & 37.22 & 9.00 \\
\hline ICMP 177001 & 2.83 & 6.44 & 1.06 & 18.75 & 3.00 \\
\hline ICMV 177002 & 4.78 & 7.89 & 1.22 & 22.78 & 3.00 \\
\hline ICMP 177002 & 2.67 & 4.11 & 0.67 & 11.94 & 3.00 \\
\hline ICMV 177003 & 2.44 & 5.56 & 0.22 & 14.44 & 2.67 \\
\hline ICMV 167005 & 3.33 & 11.78 & 2.22 & 35.00 & 4.00 \\
\hline ICMV 167014 & 5.33 & 11.11 & 2.22 & 33.33 & 6.67 \\
\hline ICMV 177004 & 4.78 & 5.33 & 0.67 & 15.00 & 7.33 \\
\hline ICMV 221 & 4.78 & 10.89 & 0.89 & 29.44 & 3.00 \\
\hline ICMV $221 \mathrm{WBr}$ & 5.39 & 12.06 & 0.89 & 32.36 & 3.33 \\
\hline ICMV IS 85327 & 4.33 & 6.78 & 1.00 & 19.44 & 7.00 \\
\hline ICMV IS 99001 & 4.22 & 12.00 & 1.33 & 33.33 & 6.00 \\
\hline ICTP 8203 & 5.39 & 10.83 & 1.33 & 30.42 & 2.33 \\
\hline ICMV IS 92222 (S) & 7.22 & 11.39 & 1.67 & 32.64 & 7.00 \\
\hline Jirani & 5.22 & 5.67 & 0.89 & 16.39 & 3.00 \\
\hline ICMV IS 90311 & 3.11 & 7.11 & 0.44 & 18.89 & 5.00 \\
\hline LCIC 9702 & 4.00 & 7.56 & 0.56 & 20.28 & 2.33 \\
\hline Sadore local & 3.33 & 10.11 & 2.78 & 32.22 & 6.33 \\
\hline Moro & 2.22 & 6.00 & 0.78 & 16.94 & 6.67 \\
\hline ICMV IS 92326 & 3.11 & 4.89 & 0.78 & 14.17 & 5.67 \\
\hline SOSAT-C88 & 3.72 & 10.56 & 0.17 & 26.81 & 3.33 \\
\hline Souna 3 & 2.78 & 5.67 & 0.67 & 15.83 & 4.67 \\
\hline ICMV IS 94206 & 3.22 & 8.67 & 0.67 & 23.33 & 6.33 \\
\hline ICMV 167002 & 4.56 & 6.67 & 1.56 & 20.56 & 6.67 \\
\hline ICMP 177004 & 4.00 & 9.89 & 1.33 & 28.06 & 6.00 \\
\hline ICMV 147141 & 4.67 & 11.44 & 1.89 & 33.33 & 7.33 \\
\hline ICMV 147142 & 5.11 & 11.33 & 1.56 & 32.22 & 7.00 \\
\hline ICMV 147143 & 4.89 & 13.22 & 0.33 & 33.89 & 6.67 \\
\hline ICMV 147144 & 4.44 & 6.11 & 2.67 & 21.94 & 5.00 \\
\hline PE00025 & 4.67 & 11.00 & 1.33 & 30.83 & 6.67 \\
\hline PE00077 & 5.11 & 10.56 & 1.67 & 30.56 & 7.33 \\
\hline PE08043 & 3.00 & 5.28 & 0.67 & 14.86 & 2.33 \\
\hline Exbornou & 3.89 & 5.44 & 1.00 & 16.11 & 6.33 \\
\hline Fpr $(38,2)$ & 0.02 & 0.42 & 0.18 & 0.45 & $<.001$ \\
\hline Mean & 4.20 & 8.64 & 1.16 & 24.50 & 5.22 \\
\hline $\mathrm{Vr}$ & $1.71 *$ & 1.05 & 1.28 & 1.02 & $7.20 * *$ \\
\hline
\end{tabular}


Table 1 continued

\begin{tabular}{llllll}
\hline Genotype & $\begin{array}{l}\text { Head miner } \\
\text { damage score }\end{array}$ & $\begin{array}{l}\text { Number of } \\
\text { larvae/panicle }\end{array}$ & $\begin{array}{l}\text { Number of } \\
\text { pupae/panicle }\end{array}$ & $\begin{array}{l}\text { Larval production } \\
\text { index (LPI) }(\%)\end{array}$ & $\begin{array}{l}\text { Agronomic } \\
\text { appreciation score }\end{array}$ \\
\hline SE \pm & 0.85 & 2.78 & 0.55 & 7.74 & 0.70 \\
LSD & 2.40 & $N S$ & $N S$ & $N S$ & 1.96 \\
\hline
\end{tabular}

***F-test significant at $P=0.05$ and 0.01 , respectively

NS non significant F value. a, 1-9 scale (where, 1 = Panicle with no damage or with single mine or 0-10\% damage and $9=$ Panicle with $>80 \%$ damage $)$ b, score $1-9(1=$ good with productive potential and lower/no insect damage and $9=$ poor productive potential with susceptibility to insect pests); (S), suceptible check

Panicle length, circumference, and compactness $(1=$ compact panicle and $3=$ loose panicle) were also recorded before harvesting by randomly selecting three plants per replication. Grain yield was recorded after harvesting and threshing the panicles. Grain iron $(\mathrm{Fe})$ and zinc $(\mathrm{Zn})$ contents were measured using the XRF machine (Oxford Instruments X-Supreme 8000 EDXRF), where the samples were exposed to the $\mathrm{X}$-rays to quantify the iron and zinc present in the pearl millet grain.

\section{Statistical analysis}

Analysis of variance (ANOVA) was conducted for the replicated data to compare the means and to identify the best performing genotypes with an $F$-test and the genotypic means were compared using the least significant difference $(L S D)$ at $P \leq 0.05$ using GenStat 14th edition (GenStat 2014). Simple correlations were calculated using excel.

\section{Results}

Expression of resistance to millet head miner and mean performance of pearl millet genotypes

Analysis of variance of head miner damage parameters revealed significant differences $(P \leq 0.01)$ between the genotypes for head miner damage and agronomic appreciation scores (Table 1). The genotypes Gamoji (2.17, 13.06\%; head miner damage score and larval production index, respectively), ICMP 177001 (2.83, 18.75\%), ICMP 177002 (2.67, $11.94 \%)$, ICMV 177003 (2.44, 14.44\%), ICMV IS 90311 (3.11, 18.89\%), LCIC 9702 (4.00, 20.28\%), Souna $3(2.78,15.83 \%)$, ICMV IS 94206 (3.22,
23.33\%), and PE08043 (3.00, 14.86\%) exhibited resistance to the head miner. These genotypes have lower larval and pupal counts leading to lower LPI (\%), indicating the presence of antibiosis resistance mechanism. The genotypes Faringuero (4.00, 28.33\%; head miner damage score and larval production index, respectively), ICMV 167005 (3.33, 35.00\%), ICMV IS 99001 (4.22, 33.33\%), Sadore local (3.33, 32.22\%), SOSAT-C88 (3.72, 26.81\%), and ICMP 177004 (4.00, $28.06 \%$ ) exhibited resistance to MHM despite high larval production index, indicating tolerance of these genotypes to MHM. The genotypes ICMV IS 89305 (3.56, 10.56\%; head miner damage score and larval production index, respectively), Moro (2.22, 16.94\%), ICMV IS 92326 (3.11, 14.17\%), and Exbornou (3.89, $16.11 \%$ ) expressed resistance to the head miner when compared with the susceptible check ICMV IS 92222 (7.22, 32.64\%).

Analysis of variance (ANOVA) for all agronomic and morphological traits revealed significant mean squares at $P \leq 0.01 / 0.05$ (Table 2). The significance of mean squares for panicle circumference, panicle compactness, agronomic score and grain yield for the season; and significant genotype $\times$ season interactions of all traits except for grain yield suggested the influence of environmental factors in the expression of these traits. The mean sum of squares for the genotypes and the genotype $\times$ season interactions were significant for all traits with a higher magnitude of genotypic mean squares.

Analysis of variance for agronomic and morphological traits revealed a significant difference $(P$ $\leq 0.01 / 0.05$ ), between the genotypes across the seasons (Table 3). The genotypes Chakti, GB 8735, ICMP 177001, ICMV 177002, ICMP 177002, ICMV 177003, ICMV 221, ICMV $221 \mathrm{WBr,} \mathrm{ICTP} \mathrm{8203,}$ Jirani, LCIC 9702, and ICMP 177004 exhibited early 


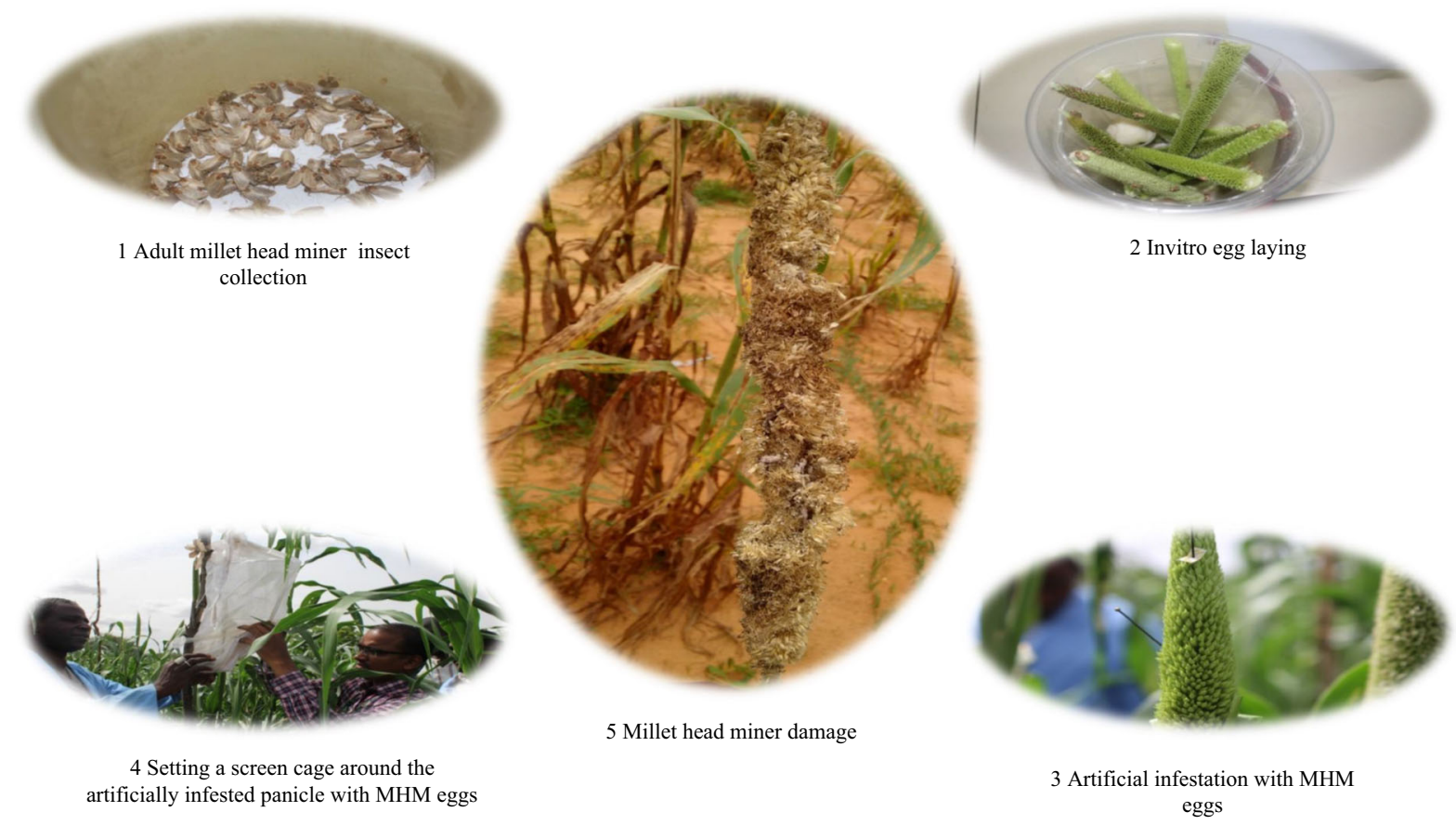

Fig. 1 Artificial screening of pearl millet genotypes using millet head miner (MHM) eggs under field conditions

flowering across seasons. Most of the genotypes performed well across seasons for plant height, panicle length, panicle circumference, and panicle compactness. Twelve genotypes exhibited stable performance for grain $\mathrm{Fe}$ and $\mathrm{Zn}$ contents across the seasons. The genotypes ICMP 177001, ICMP 177002, ICMV 177003, and Moro exhibited resistance to MHM and had consistent grain Fe content across seasons (ranging from 44 to $70 \mathrm{ppm}$ ). The genotypes ICMV IS 89305, ICMV IS 90309, Gamoji, ICMV 177001, ICMV 167005, ICMV 167014, ICMV IS 92222, SOSAT-C88, Souna 3, ICMV IS 94206, ICMV 167002, ICMP 177004, ICMV 147141, ICMV 147142, ICMV 147143, ICMV 147144 and PE00025 performed well for grain yield, across seasons.

The relationship between the head miner damage and grain yield is depicted in Fig. 2. Scatter plot analysis between the head miner damage and grain yield placed the genotypes into three groups. The genotypes with high yield and head miner resistance were shown in Group 1. The genotypes exhibiting resistance but yielding low were grouped in Group 2 . And group 3 represents the susceptible genotypes with varying grain yield levels. Most of the susceptible genotypes were also high yielding $(>1.50 \mathrm{t} / \mathrm{ha})$.
Association between the MHM resistance, morphological and agronomic parameters

Significant and positive correlation was observed between head miner damage score and larval production index $\left(\mathrm{r}=0.59^{* *}\right)$ (Table 4). Agronomic appreciation score showed positive and significant correlation with days to $50 \%$ flowering $(r=0.67 * *)$, plant height $(\mathrm{r}=0.49 * *)$, panicle length $(\mathrm{r}=0.52 * *)$ and grain yield $\left(\mathrm{r}=0.66^{* *}\right)$ and significant negative correlation with grain $\mathrm{Fe}(\mathrm{r}=-0.52 * *)$ and $\mathrm{Zn}$ $\left(\mathrm{r}=-0.43^{* *}\right)$ contents.

Association between the morphological and agronomic traits revealed significant and positive correlation of days to $50 \%$ flowering with plant height $(\mathrm{r}=0.49 * *)$, panicle length $(\mathrm{r}=0.52 * *)$ and grain yield $(r=0.60)$ (Table 4$)$. Grain Fe and $\mathrm{Zn}$ contents exhibited significant negative correlations with days to $50 \%$ flowering $\left(\mathrm{r}=-0.67 * *,-0.57^{* *}\right.$; grain $\mathrm{Fe}$ and $\mathrm{Zn}$, respectively), plant height $\left(\mathrm{r}=-0.40^{* *}\right.$, $\left.-0.36^{* *}\right)$ and panicle length $(\mathrm{r}=-0.72 * *$, $\left.-0.77^{* *}\right)$ and significant positive correlation with panicle diameter $\left(\mathrm{r}=0.36^{* *}, 0.32 *\right)$ and panicle compactness $\left(r=0.46^{* *}, 0.34 *\right)$. Significant negative correlation was recorded between grain yield and 


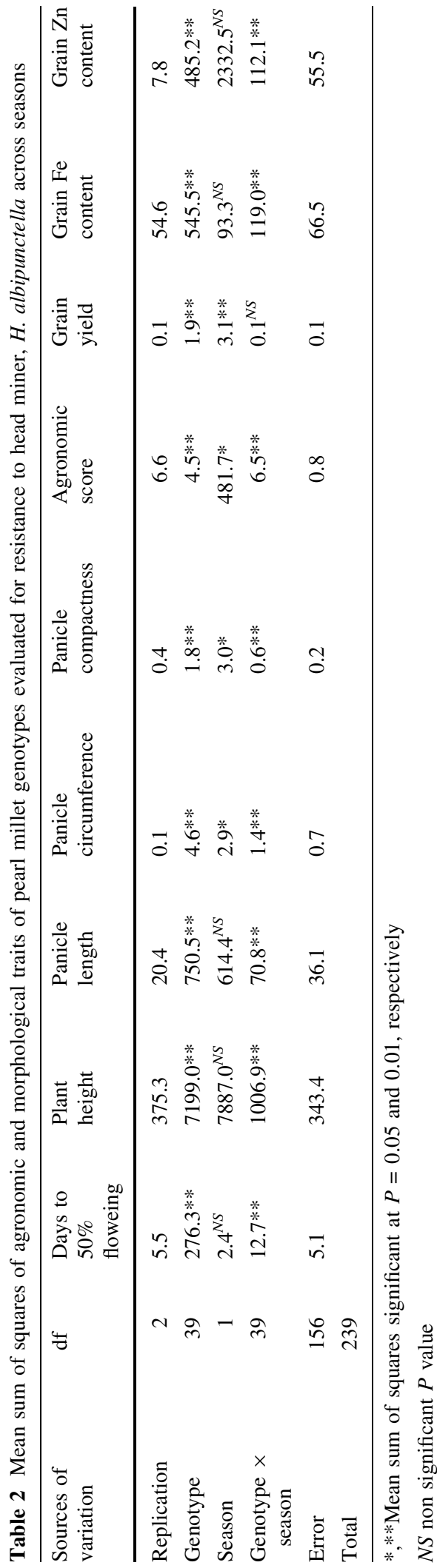

grain $\mathrm{Fe}\left(\mathrm{r}=-0.70^{* *}\right)$ and grain yield and grain $\mathrm{Zn}$ $(\mathrm{r}=-0.64 * *)$ contents. Highly significant and positive correlation was seen between grain $\mathrm{Fe}$ and $\mathrm{Zn}$ contents $\left(\mathrm{r}=0.96^{* *}\right)$.

\section{Discussion}

Millet head miner $H$. albipunctella is the most devastating pest of pearl millet in the Sahel, a deadly problem in the food insecure region where no other crop is grown except pearl millet (Nwanze and Youm 1995). Genetic variability is a very important factor for breeding. In the present study, analysis of variance for head miner resistance and agro-morphological traits indicated the presence of genetic variability for MHM in WCA. This existing genetic variability in pearl millet can be exploited in building up the head miner resistance with increased crop yields (Tooker and Frank 2012). The present study has reported higher genotypic mean squares than the seasonal interactions, indicating the superiority of the genetic factors over environment in the inheritance of the studied traits, which is very important to breed stable pearl millet genotypes across the region.

Few of the genotypes exhibited antibiosis resistance mechanism to MHM, which is a primary category of resistance that can negatively impact the biology of a pest through an increase in mortality, reduced growth, longevity, and fecundity (Painter 1951; Smith 2005). The genotypes ICMV 167005, ICMV IS 99001, Sadore local, SOSAT-C88, ICMV IS 94206 and ICMP 177004 exhibited tolerance to head miner damage. Tolerance in the genotypes reduces the negative effects of herbivory on plant fitness after herbivory has occurred while maintaining insect populations similar to those seen on susceptible plants. The antibiosis resistance and tolerance of pearl millet genotypes to MHM can be effectively utilized in developing new hybrids or OPV's.

In general, early planted or early maturing pearl millet becomes heavily infested with MHM (Gahukar et al. 1986; Nwanze and Shivakumar 1990; Eisa et al. 2007), but in the present study few of the pearl millet genotypes with early flowering exhibited resistance to MHM indicating the possibility of breeding early maturing pearl millet with MHM resistance which is suitable for the semi-arid conditions existing in the Sahel. Since the present experiment was under the no- 


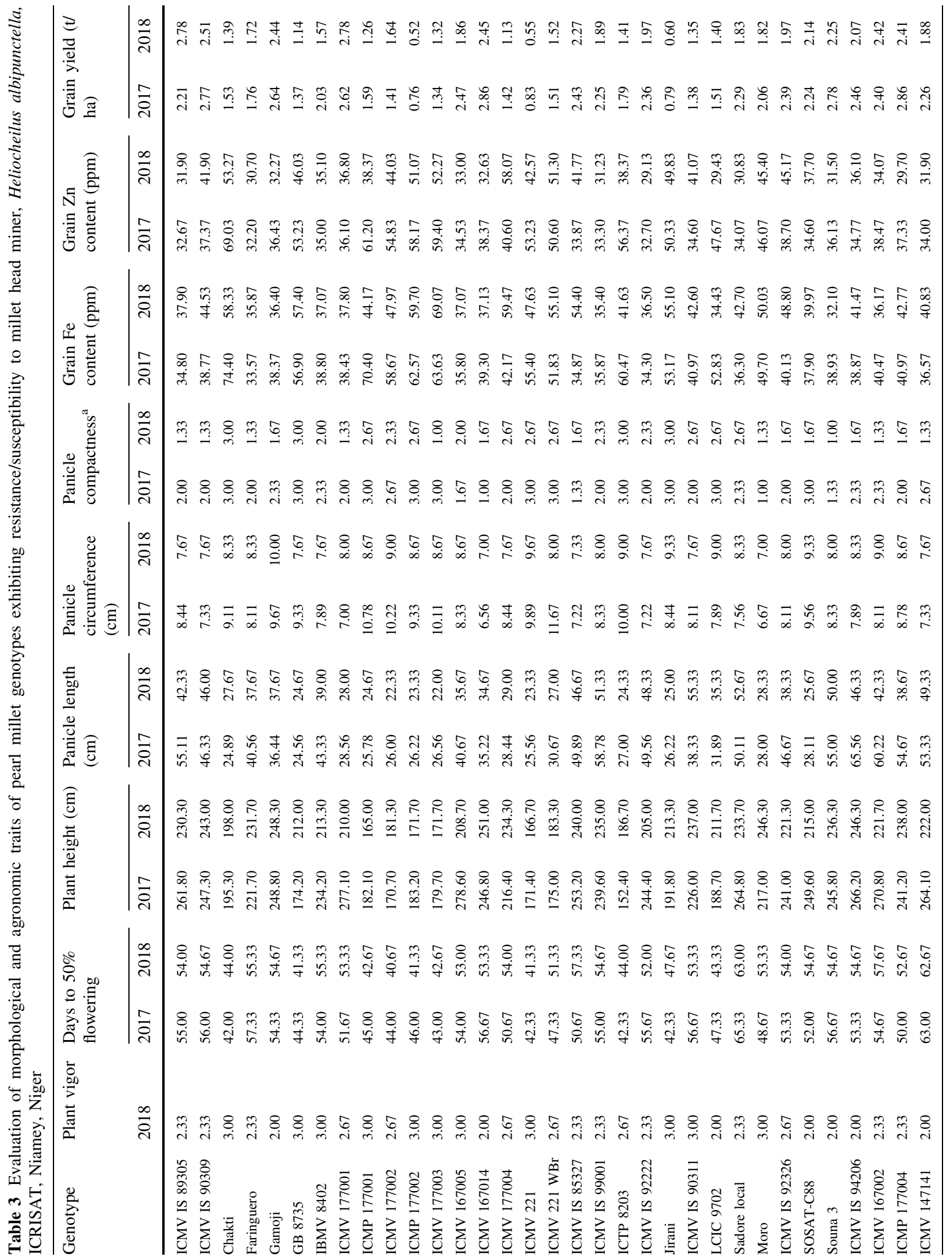




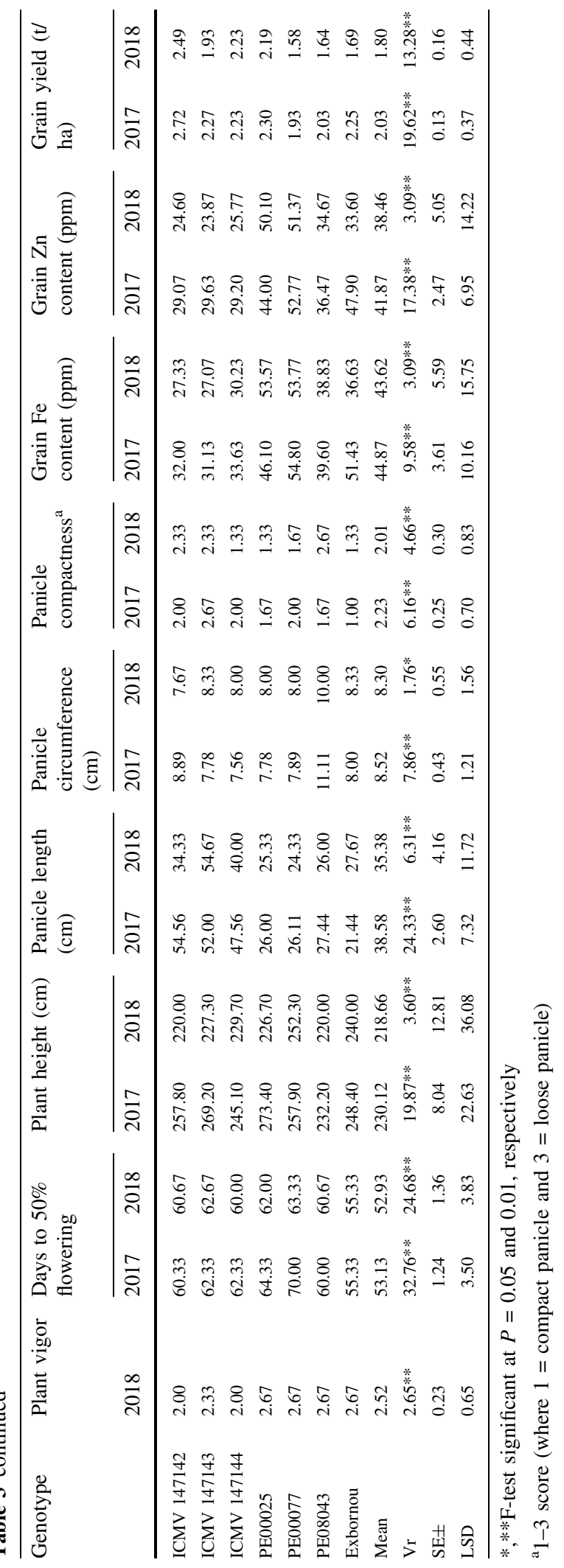


choice condition and hence there was no possibility of escapes and the identified early maturing resistant sources can deliver best against MHM and also avoid the terminal drought stress which is very common in the Sahel region.

The primary objective of plant breeding is to improve the grain yield. Hence, identification of the genotypes with MHM resistance and with high grain yield will serve the purpose leading to sustainability. The genotypes ICMV IS 89305, Gamoji, ICMV 167005, SOSAT-C88, Souna 3, ICMV IS 94206 and ICMP 177004 exhibited resistance to MHM with high per se performance. These genotypes can be effectively utilized in breeding head miner resistance cultivars with good grain yield which can benefit the resource-poor farmers of WCA. Some of the genotypes exhibited resistance to millet head miner but were yielding low, and can be utilized in building up the head miner resistance in high yielding susceptible cultivars.
In the present scenario plant breeders cannot aim at a single trait for improvement. Instead one has to have a holistic approach in developing the cultivars. Identifying the high micronutrient genotypes and transferring that trait to a high yielding MHM resistant genotype leads to the cost-effective and sustainable agricultural strategy to reduce micronutrient malnutrition arising from $\mathrm{Fe}$ and $\mathrm{Zn}$ deficiencies (Rai et al. 2016; Manwaring et al. 2016), which is vulnerable in the semi-arid regions of Asia and Africa. Significant differences were seen in the grain $\mathrm{Fe}$ and $\mathrm{Zn}$ traits, indicating the presence of variability for these traits in the material used for this study. The variability for grain $\mathrm{Fe}$ and $\mathrm{Zn}$ present in the material can be exploited in generating high yielding varieties/hybrids with elevated levels of these micronutrients. The genotypes ICMP 177001, ICMP 177002, ICMV 177003, and Moro have high grain Fe and $\mathrm{Zn}$ content and exhibited resistance to head miner damage but have moderate grain yield. The genotype Chakti has high grain Fe content but is susceptible to millet head

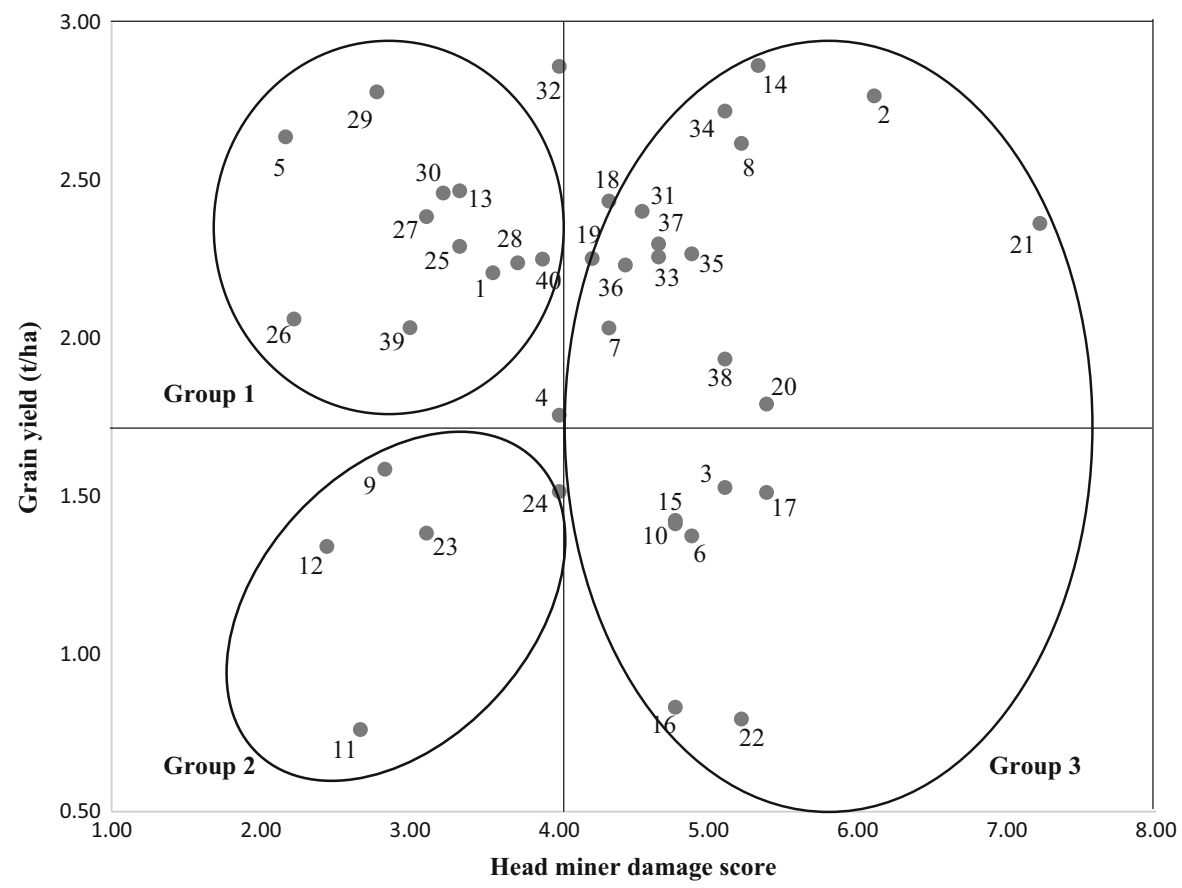

Fig. 2 Relationship between the grain yield and millet head miner, Heliocheilous albipunctella damage in pearl millet (ICRISAT, Niamey, Niger) (1 ICMV IS 89305, 2 ICMV IS 90309, 3 Chakti, 4 Faringuero, 5 Gamoji, 6 GB 8735, 7 IBMV 8402, 8 ICMV 177001, 9 ICMP 177001, 10 ICMV 177002, 11 ICMP 177002, 12 ICMV 177003, 13 ICMV 167005, 14 ICMV 167014, 15 ICMV 177004, 16 ICMV 221, 17 ICMV 221 WBr,
18 ICMV IS 85327, 19 ICMV IS 99001, 20 ICTP 8203, 21 ICMV IS 92222, 22 Jirani, 23 ICMV IS 90311, 24 LCIC 9702, 25 Sadore Local, 26 Moro, 27 ICMV IS 92326, 28 SOSAT-C88, 29 Souna 3, 30 ICMV IS 94206, 31 ICMV 167002, 32 ICMP 177004, 33 ICMV 147141, 34 ICMV 147142, 35 ICMV 147143, 36 ICMV 147144, 37 PE0025, 38 PE0077, 39 PE08043, 40 Exbornou) 


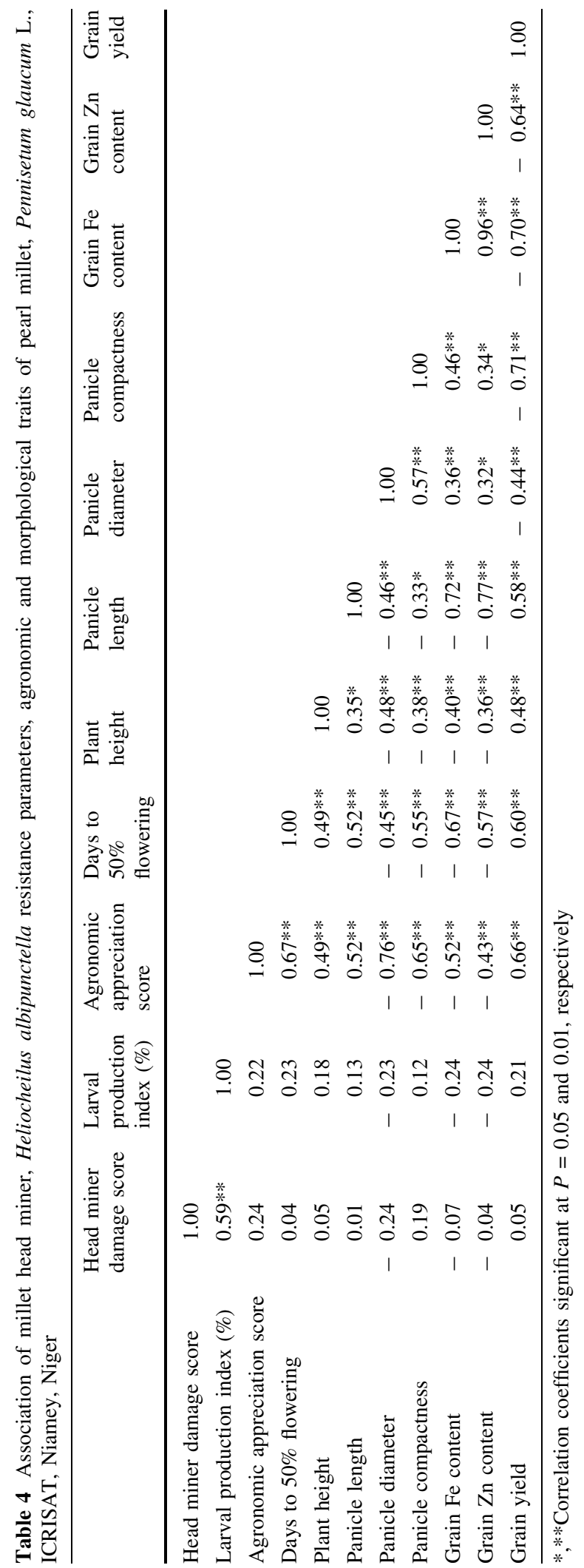


miner. Hence, these genotypes can be improved further for grain yield and also can be effectively utilized in breeding hybrids/OPV's for sustainable agriculture. Identifying the resistance sources for MHM, with high grain Fe and Zn makes it a promising crop to address grain yield losses due to head miner and micronutrient malnutrition, leading to sustainable food security in WCA.

The knowledge of the relationship between the traits is very important for a breeder to combine these traits into an improved genetic background. The correlation studies revealed a positive association of head miner damage with the larval production index and negligible negative association with grain $\mathrm{Fe}$ and Zn contents indicating the feasibility in developing the pearl millet cultivars with MHM resistance along with high grain $\mathrm{Fe}$ and $\mathrm{Zn}$ contents. Highly significant and positive correlation of grain $\mathrm{Fe}$ with $\mathrm{Zn}$ indicates the linkage of the genes and/or under the influence of pleiotropy, which encourages concurrent genetic improvement. Similar results have been reported earlier (Velu et al. 2011; Govindaraj et al. 2013). Grain yield is positively associated with plant height, panicle length, and negatively associated with panicle compactness indicating care should be taken while breeding for these traits. The grain $\mathrm{Fe}$ and $\mathrm{Zn}$ densities had a significant negative correlation with grain yield. Similar results were reported earlier in pearl millet hybrids (Rai et al. 2012), and sorghum (Reddy et al. 2005). Therefore, careful selection should be followed in the initial breeding stages to develop cultivars with high grain yield and $\mathrm{Fe}$ and $\mathrm{Zn}$ contents. The high positive correlations between the agronomic traits can be helpful in allowing a simultaneous improvement of both the characters through correlated responses to selection. Association of these studied traits indicated that proper care should be taken while breeding for MHM resistance along with suitable agronomic and morphological traits.

\section{Conclusions}

Considerable progress has been made in developing high yielding varieties in the last five years at ICRISAT in WCA. Identification of resistance sources to millet head miner with high grain $\mathrm{Fe}$ and $\mathrm{Zn}$ and not compromising on grain yield can lead to sustainable development in WCA. The present study has identified the resistance sources for millet head miner with high grain $\mathrm{Fe}$ and $\mathrm{Zn}$ contents and can be effectively utilized in developing the high yielding head miner resistant pearl millet hybrids/OPV's. The genotypes ICMP 177001 and ICMV 177003 can be improved and released in the public domain as they performed well for MHM resistance and also have high grain Fe and Zn contents after careful study under multi-environment conditions. This study paves the way for applied genetic improvement of pearl millet host plant resistance to millet head miner along with the grain Fe and $\mathrm{Zn}$. Genotypes with diverse MHM resistance and agronomic and morphological traits can be effectively utilized in breeding MHM resistant pearl millet, which can increase the effectiveness of biocontrol agents.

Acknowledgements We are thankful to the millet breeding and entomology teams of ICRISAT-Sahelian Center, Niger for their help in carrying out artificial infestation under field conditions. We are also thankful to SERB, Govt. of India for their financial support through SERB-OPDF fellowship and to Harvest Plus, CGIAR Research Program on Grain Legumes and Dryland Cereals (CRP-GLDC) and Collaborative Crop Research Program (CCRP) of the McKnight Foundation, Minneapolis, MN projects for the financial support to carry out the field experiments during the study.

\section{References}

Ba MN, Baoua IB, N'Diaye M, Dabire-Binso C, Sanon A, Tamo M (2013) Biological control of the millet head borer, $\mathrm{He}$ liochilius albipunctalla in the Sahelian region by augmentative releases of the parasitoid wasp, Habrobracon hebetor effectiveness and farmers' perceptions. Phytoparasitica 41:569-576

Baoua IB, Ba MN, Amadou L, Oumarou N, Payne W, Roberts JD, Stefanova K, Nansen C (2014) Estimating effect of augmentative biological control on grain yields from individual pearl millet fields. J Appl Entomol 138:281-288

Bidinger FR, Hash CT (2004) Pearl millet. In: Nguyen HT, Blum A (eds) Physiology and biotechnology integration for plant breeding. Marcel Dekker, New York, pp 225-270

Dwivedi SL, Sahrawat KL, Rai KN, Blair MW, Andersson MS, Pfeiffer W (2012) Nutritionally enhanced staple food crops. Plant Breed Rev 36:169-291. https://doi.org/10. 1002/9781118358566.ch3

Eisa MA, Elamin EM, Elbadawi A, El-Hassan AEB, Rudwan MK, Ratschker UM, Roth M (2007) Ecological characteristics of the millet head miner, Heliocheilus albipunctella (Lepidoptera: Noctuidae): a pest on pearl millet in Sudan, pp 1-7. In: Proceedings, Tropentag 2007. Conference on international agricultural research for development, 9-11 October 2007, University of KasselWitzenhaussen and University of Gottingen, Gottingen, Germany 
FAOSTAT (2016) Food and Agriculture Organisation of the United Nations. Accessed on 12 April 2019. http://www. fao.org/faostat/en/\#data/QC

FAOSTAT (2017) Food and agriculture organisation of the United Nations. Accessed on 30 Nov 2019. http://www. fao.org/faostat/en/\#data/QC

Gahukar RT, Ba MN (2019) An Updated Review of Research on Heliocheilus albipunctella (Lepidoptera: Noctuidae), in Sahelian West Africa. J Integr Pest Manag 10(1):1-9. https://doi.org/10.1093/jipm/pmz003

Gahukar RT, Guevremont H, Bhatnagar VS, Doumbia YO, Ndoye M, Pierrard G (1986) A review of the pest status of the millet spike worm, Raghuva albipunctella de Joannis (Noctuidae: Lepidoptera) and its management in the Sahel. Int J Trop Insect Sci 7:457-463

GenStat (2014) Genstat for Windows 18th Edition. VSN International, Hemel Hempstead, UK. Web page: Genstat.co.uk

Govindaraj M, Rai KN, Shanmugasundaram P, Dwivedi SL, Sahrawat KL, Muthaiah AR, Rao AS (2013) Combining ability and heterosis for grain iron and zinc densities in pearl millet. Crop Sci 53:507-517

Guerci MJ, Norton GW, Ba MN, Baoua I, Alwang J, Amadou L, Moumouni O, Karimoune L, Muniappan R (2018) Economic feasibility of an augmentative biological control industry in Niger. Crop Prot 110:34-40

Harinarayana GK, Anand Kumar A, Andrews DJ (1999) Pearl millet in global agriculture. In: Khairwal IS, Rai KN, Andrews DJ, Harinarayana G (eds) Pearl Millet breeding. Oxford and IBH: New Delhi, India, pp 479-506

Hash CT (1999) Pearl millet breeding. In: Proceedings of the international Pearl Millet workshop, Planaltina, Brazil, Jun 9-10, 1999. In: Lopes de Farias Neto A, Fernando Amabile R, Martins Netto DA, Yamashita T, Gocho H (eds) Embrapa Cerrados: Planaltina, D.F., Brazil, pp 13-30

Kabore A, Ba MN, Dabire-Binso C, Sanon A (2019) Towards development of a parasitoid cottage industry of Habrobracon hebetor (Say): optimum rearing and releases conditions for successful biological control of the millet head miner Heliocheilus albipunctella (De Joannis) in the Sahel. Int J Trop Insect Sci. https://doi.org/10.1007/ s42690-019-00005-w

Krall S, Youm O, Kogo SA (1995) Panicle insect pest damage and yield loss in pearl millet. In: Nwanze KF, Youm O (eds) Proceeding of an international consultative workshop on panicle insect pest of Sorghum and Millet, ICRISAT Sahelian Centre, Niamey, Niger. ICRISAT: Patancheru 502324, Andhra Pradesh, India, pp 135-145

Manwaring HR, Bligh HFJ, Yadav R (2016) The challenges and opportunities associated with biofortification of Pearl Millet (Pennisetum glaucum) with elevated levels of grain iron and zinc. Front Plant Sci 7:1-15. https://doi.org/10. 3389/fpls.2016.01944

Nwanze KF, Shivakumar MVK (1990) Insect pests of pearl millet in Sahelian West Africa. II. Raghuva albipunctalla (de Joannis) (Noctuidae: Lepidoptera): distribution, population dynamics and assessment of crop damage. Int J Pest Manag 36:59-65

Nwanze KF, Harris KM (1992) Insect pests of pearl millet in West Africa. Rev Agric Entomol 80:1132-1185
Nwanze KF, Youm O (1995) Panicle insect pests of sorghum and pearl millet: proceedings of an international consultative workshop, 4-7 October 1993, ICRISAT Sahelian Centre, Niamey, Niger. ICRISAT Patancheru, India

Painter RH (1951) Insect resistance in crop plants. University of Kansas Press, Lawrence, p 520

Payne WH, Tapsoba IB Baoua, Malick BN, N'Diaye M, DabireBinso C (2011) On-farm biological control of the pearl millet head miner: realization of 35 years of unsteady progress in Mali, Burkina Faso and Niger. Int J Agric Sustain 9(1):186-193

Poncet V, Lamy F, Enjalbert J, Joly H, Sarr A, Robert T (1998) Genetic analysis of the domestication syndrome in pearl millet (Pennisetum glaucum L., Poaceae): inheritance of the major characters. Heredity 81:648-658

Rai KN, Govindaraj M, Rao AS (2012) Genetic enhancement of grain iron and zinc content in pearl millet. Qual Assur Saf Crop 4:119-125. https://doi.org/10.1111/j.1757-837X. 2012.00135.x

Rai KN, Yadav OP, Govindaraj M, Wolfgang P, Yadav HP, Rajpurohit BS, Patil HT, Kanatti A, Rathore A, Rao AS, Shivade H (2016) Grain iron and zinc densities in released and commercial cultivars of pearl millet (Pennisetum glaucum). Indian J Agric Sci. 86(3): 291-296

Reddy BVS, Ramesh S, Longvah T (2005) Prospects of breeding for micronutrients and $\beta$-carotene-dense sorghums. Int Sorghum Millets Newsl 46:10-14

Schlenker W, Lobell DB (2010) Robust negative impacts of climate change on African agriculture. Environ Res Lett. https://doi.org/10.1088/1748-9326/1/014010

Smith CM (2005) Plant resistance to arthropods: molecular and conventional approaches. Springer, Dordrecht, p 423

Stich B, Haussmann BIG, Pasam R, Bhosale S, Hash CT, Melchinger AE, Parzies HK (2010) Patterns of molecular and phenotypic diversity in pearl millet [Pennisetum glaucum (L.) R. Br.] from West and Central Africa and their relation to geographical and environmental parameters. BMC Plant Biol 10:216. https://doi.org/10.1186/ 1471-2229-10-216

Tooker JF, Frank SD (2012) Genotypically diverse cultivar mixtures for insect pest management and increased crop yields. J Appl Ecol 49:974-985. https://doi.org/10.1111/j. 1365-2664.2012.02173.x

Velu G, Rai KN, Muralidharan V, Longvah T, Crossa J (2011) Gene effects and heterosis for grain iron and zinc density in pearl millet (Pennisetum glaucum (L.) R. Br.). Euphytica 180:251-259. https://doi.org/10.1007/s10681-011-0387-0

Yadav OP, Rai KN (2013) Genetic improvement of pearl millet in India. Agric Res 2:275-292

Youm O, Kumar AK (1995) Screening and breeding for resistance to millet head miner. In: Nwanze KF, Youm O (eds) Panicle insect pests of sorghum and Pearl Millet: proceedings of an international consultative workshop, 4-7 October, ICRISAT Sahelian Center, Niamey, Niger, pp. 201-209

Youm O, Owusu EO (1998) Assessment of yield loss due to the millet head miner, Heliocheilus albipunctella (Lepidoptera: Noctuidae) using a damage rating scale and regression analysis in Niger. Int J Pest Manag 44:119-121 
Youm O, Yacouba M, Kumar AK (2001) An improved infestation technique using eggs of the millet head miner ( $\mathrm{He}$ liocheilus albipunctella) (Lepidoptera: Noctuidae) in millet resistance screening. Int J Pest Manag 47:289-292
Publisher's Note Springer Nature remains neutral with regard to jurisdictional claims in published maps and institutional affiliations. 